\title{
Correlating Prior Austenite Grain Microstructure, Microscale Deformation and Fracture of Ultra-High Strength Martensitic Steels
}

\author{
Xinzhu Zheng ${ }^{1}$, Hassan Ghassemi-Armaki ${ }^{2}$, Karl T. Hartwig ${ }^{1}$ and Ankit Srivastava ${ }^{1, *(D)}$ \\ 1 Department of Materials Science and Engineering, Texas A\&M University, College Station, TX 77843, USA; \\ xinzhu_zheng@tamu.edu (X.Z.); thartwig@tamu.edu (K.T.H.) \\ 2 ArcelorMittal Global R\&D—East Chicago, East Chicago, IN 46312, USA; Hassan.Ghassemi@arcelormittal.com \\ * Correspondence: ankit.sri@tamu.edu; Tel.: +1-979-458-9841
}

check for

updates

Citation: Zheng, X.;

Ghassemi-Armaki, H.; Hartwig, K.T.;

Srivastava, A. Correlating Prior

Austenite Grain Microstructure,

Microscale Deformation and Fracture of Ultra-High Strength Martensitic Steels. Metals 2021, 11, 1013. https:// doi.org/10.3390/met11071013

Academic Editor: Alexander V. Shelyakov

Received: 1 June 2021

Accepted: 18 June 2021

Published: 24 June 2021

Corrected: 10 February 2022

Publisher's Note: MDPI stays neutral with regard to jurisdictional claims in published maps and institutional affiliations.

Copyright: (C) 2021 by the authors. Licensee MDPI, Basel, Switzerland. This article is an open access article distributed under the terms and conditions of the Creative Commons Attribution (CC BY) license (https:// creativecommons.org/licenses/by/ $4.0 /)$.

\begin{abstract}
Herein, we correlate the prior austenite grain (PAG) microstructure to deformation and fracture mechanisms of an ultra-high strength martensitic steel. To this end, a low-carbon martensitic steel is subjected to five heat-treatments and the PAG microstructure in the material is reconstructed from the EBSD inverse pole figure maps of the martensitic microstructure. The deformation and fracture response of all heat-treated materials are characterized by in situ tension tests of dog-bone and single-edge notch specimens that allow us to capture both the macroscopic mechanical response and the evolution of microscopic strains via microscale digital image correlation. The experimental results, together with microstructure-based finite element analysis, are then used to elucidate the effect of the PAG microstructure on the mechanical response of the material. Our results show that the interaction between the heterogeneous deformation fields induced by the notch and the bimodal PAG size distribution leads to an increase in the propensity of shear deformation and degradation in the fracture response of the material with increasing heat-treatment temperature and time. Our results also suggest that achieving a unform distribution of fine grains is an effective way to enhance both the strength and fracture properties of this class of materials.
\end{abstract}

Keywords: microstructure characterization; in situ tension test; plasticity; fracture behavior; digital image correlation; martensitic steels; finite element analysis

\section{Introduction}

Advanced high-strength steels (AHSS) are one of the most attractive materials for automotive applications, as they offer a wide range of microstructures and mechanical properties [1-3]. Different AHSS are used in different parts of a vehicle to meet the diverse manufacturing and performance requirements $[1,4]$. For example, the parts in the front of a vehicle usually have complex shapes and call for materials with good formability. While the need to enhance the crashworthiness of a vehicle calls for materials with high strength and toughness. However, the strength-ductility (toughness) trade-off limits the strength level of AHSS that can be used in the manufacturing of complex shapes. Nevertheless, during the front-impact collision of a vehicle, there is a large space for the structure to deform and absorb energy before the impact endangers the passengers. On the contrary, during a side-impact collision, there is very limited space for the structure to deform. Thus, vehicle parts such as the A-pillar that supports the windshield, the B-pillar between the front and the rear doors, and the beams in the vehicle doors call for materials with ultra-high strength. Advanced low-carbon martensitic steels with a strength level more than 1.2 GPa are the most widely sought-after structural materials for these parts, to enhance the overall crashworthiness of a vehicle [5,6].

For automotive applications, press hardening is used extensively to economically manufacture ultra-high strength martensitic steel parts. This process involves first heating 
the steel above the upper critical temperature (Ac3) to achieve a fully austenitic microstructure, which is then followed by hot press forming to form complex shapes, and finally rapid quenching to achieve a fully martensitic microstructure. In this process, the temperature and time of the heat-treatment can be varied to achieve different microstructures. In general, the heat-treatment temperature and time during this processes varies from $900{ }^{\circ} \mathrm{C}$ to $950{ }^{\circ} \mathrm{C}$, and 4 to $10 \mathrm{~min}$, respectively [7], to obtain a fully austenitic microstructure and avoid undesirable grain coarsening. The final microstructure of the material comprises lath-like martensite with a hierarchical structure consisting of laths, blocks, and packets within prior austenite grains (PAGs) [8-12].

The mechanical properties of these materials are determined by the chemical composition, particularly carbon content [13-16], and by the microstructural features, such as block and packet sizes that are proportional to the PAG size $[17,18]$. In general, the strength and hardness of low-carbon martensitic steels have been found to increase with decreasing PAG size [17-25]. However, the dependence of ductility of the material on the PAG size is rather ambiguous and it does not simply follow the typical strength-ductility trade-off associated with microstructure refinement. Specifically, one study [23] has reported that the ductility of low-carbon martensitic steels decreases with decreasing PAG size (in this study PAG size varied in the range 7-17 $\mu \mathrm{m}$ ), others $[20,24]$ have reported that it increases with decreasing PAG size (in these studies PAG size varied in the range 10-125 $\mu \mathrm{m}$ ), and still others [21,25] have reported that it is somewhat insensitive to the PAG size (in these studies PAG size varied in the range 5-35 $\mu \mathrm{m}$ ). While the fracture properties, such as notch ductility as characterized by double-edge notch tension tests $[23,25]$ and impact toughness as characterized by Charpy impact tests [20-22,24], have been reported to increase with decreasing PAG size for PAG size $\geq 10 \mu \mathrm{m}$.

There is a great interest in understanding the effect of the PAG size on the deformation and fracture response of low-carbon martensitic steels with an average PAG size less than tens of microns. This is because even though the standard press hardening process qualitatively results in fine microstructures that impart ultra-high strength, technologically it is important to understand the effect of small variations in the process parameters (heattreatment temperature and time) on the final microstructure and mechanical performance of the material. Furthermore, as noted in the preceding paragraph, the current state of understanding of the effect of the PAG size raises more questions than it answers. In particular, there are the following two lingering questions that need to be answered: (i) What is the effect of the PAG size on the ductility and fracture response of low-carbon martensitic steels with a very fine microstructure? (ii) If at all, why do the fracture properties of low-carbon martensitic steels degrade with increasing PAG size? To answer these questions, we have carried out a series of heat-treatments of a low-carbon martensitic steel to vary the PAG microstructure in the material. The resultant microstructures are characterized by electron backscatter diffraction (EBSD), which are then used to reconstruct the PAGs. Next, the deformation and fracture response of all the heat-treated materials are characterized by in situ tension tests of dog-bone and single-edge notch specimens under a high-resolution optical microscope, allowing us to capture both the macroscopic mechanical response and the distribution of microscopic strains via microscale digital image correlation (DIC). Finally, microstructure-based finite element analyses are carried out to rationalize the effect of the PAG microstructures on the observed mechanical response of the material.

Our results show that both the bimodality and average size of the PAGs in the lowcarbon martensitic steel increases significantly with increasing heat-treatment temperature and time, for the range of temperature and time considered in this work. Despite this, their yield and tensile strength levels, as well as the ductility, only decrease slightly with increasing average PAG size. However, the notch strength and ductility, as well as the crack-tip opening displacement (CTOD) at crack growth initiation as characterized by the tension tests of the single-edge notch specimens, decrease significantly with increasing average PAG size. This contrasts with any analysis based on classical engineering fracture mechanics that will predict a very similar fracture response for materials that exhibit 
a very similar stress-strain response under uniaxial tension. The results of our in situ tests, together with microstructure-based finite element analysis, clearly elucidate that it is the interaction of the heterogeneous deformation fields induced by the notch and the bimodal PAG size distribution that leads to an increase in the propensity of shear deformation and, in turn, degradation in the fracture response of the martensitic steel with increasing heat-treatment temperature and time (or average PAG size). A major conclusion derived from our results is that achieving a unform distribution of fine grains is an effective way to increase the strength levels and enhance the fracture properties of the low-carbon martensitic steels.

\section{Materials and Methods}

The low-carbon ultra-high strength martensitic steel considered in this work is a cold rolled fully martensitic steel by ArcelorMittal with nominal chemical composition of $\sim 0.25 \mathrm{wt}$. \% carbon, $\sim 0.4 \mathrm{wt}$. \% silicon and $\sim 1.4 \mathrm{wt}$. \% manganese. This steel has an $\mathrm{A}_{\mathrm{C}} 3$ temperature of $863{ }^{\circ} \mathrm{C}$ [25]. To understand the effect of the variability in the process parameters, the steel was subjected to the following five heat-treatments: $870{ }^{\circ} \mathrm{C}$ for $4 \mathrm{~min}$, $870{ }^{\circ} \mathrm{C}$ for $10 \mathrm{~min}, 930{ }^{\circ} \mathrm{C}$ for $4 \mathrm{~min}, 930^{\circ} \mathrm{C}$ for $10 \mathrm{~min}$ and $950{ }^{\circ} \mathrm{C}$ for $10 \mathrm{~min}$. All heattreatments were followed by rapid cooling to achieve fully martensitic microstructure. The deformation and fracture response of all five heat-treated materials were characterized via in situ tension tests. The microstructure characterization of the undeformed material and fractographic analysis of the fractured specimens were carried out using a (TescanFERA3) scanning electron microscope (SEM) equipped with secondary electron (SE) and EBSD detectors.

The in situ tension tests were carried out using a miniature tensile stage (Kammrath \& Weiss, Schwerte, Germany) under a high-resolution digital optical microscope (DSX510, Olympus, Tokyo, Japan). For tension tests, sub-sized flat dog-bone, and single-edge notch specimens with the axis along the rolling direction of the steel sheets were machined using wire electrical discharge machining (EDM) from all five heat-treated materials. The length and width of the gauge section of the dog-bone specimens were $8 \mathrm{~mm}$ and $3 \mathrm{~mm}$, respectively. The single-edge notch specimens also had the same dimensions, but they contained an edge notch of depth $1.5 \mathrm{~mm}$. The notches were machined using a diamond wire in the center of the gauge section. The final tip radius of the diamond wire machined notches was $\approx 45 \mu \mathrm{m}$. Although the objective of this work is not to measure standard mechanical properties, but to correlate the effects of the PAG microstructure on the mechanical response of martensitic steels, we do, however, note that the aspect ratios of the sub-sized dog-bone and single-edge notch specimens are in compliance with the ASTM [26] and British standards [27], respectively. The surfaces of all the specimens were mechanically ground using 320 to 1200 grit $\mathrm{SiC}$ grinding papers and fine polished with polycrystal diamond suspension followed by $0.05 \mu \mathrm{m}$ alumina suspension. The final thickness of the polished specimens was approximately $1.08 \mathrm{~mm}$. The polished surfaces of all the specimens were decorated with finely dispersed $1 \mu \mathrm{m}$ polycrystalline diamond particles. All tension tests were carried out at a crosshead speed of $4 \mu \mathrm{m} / \mathrm{s}$ (giving a nominal strain rate of $0.5 \times 10^{-3} \mathrm{~s}^{-1}$ for the dog-bone specimens).

The in situ tension tests were interrupted at regular intervals to capture high-resolution $(0.34 \mu \mathrm{m} /$ pixel) optical images of the polished surface of the specimens, which were decorated with diamond particles. The series of images captured during tension tests were then used to carry out microscale DIC by tracking the micron size diamond particles. At least two sets of in situ tension tests and one set of uninterrupted ex situ tension tests of both the dog-bone and single-edge notch specimens of all five heat-treated materials were carried out. The DIC analyses were performed using the Ncorr open-source DIC software [28] with a subset radius of 30 pixels and inter subset spacing of 1 pixel. The displacement fields measured by DIC were then used to estimate the Green-Lagrange strain. 


\section{Results}

\subsection{Material Microstructure}

The EBSD inverse pole figure (IPF) maps of the low-carbon fully martensitic steel following five heat-treatments are shown in Figure 1. The rolling direction is along the horizontal axis of all the IPF maps, and each IPF map represents a $150 \times 200 \mu^{2}$ area. The electron beam was scanned in steps of $0.3 \mu \mathrm{m}$ at a voltage of $20 \mathrm{kV}$; the EBSD pattern was indexed using the Fe-bcc phase. The different colors in the IPF maps represent the blocks of the martensitic microstructure. As can be seen from the IPF maps, on average the block size in the microstructure increased significantly from the heat treatment condition of $870{ }^{\circ} \mathrm{C}$ for $4 \mathrm{~min}$ to $950{ }^{\circ} \mathrm{C}$ for $10 \mathrm{~min}$.
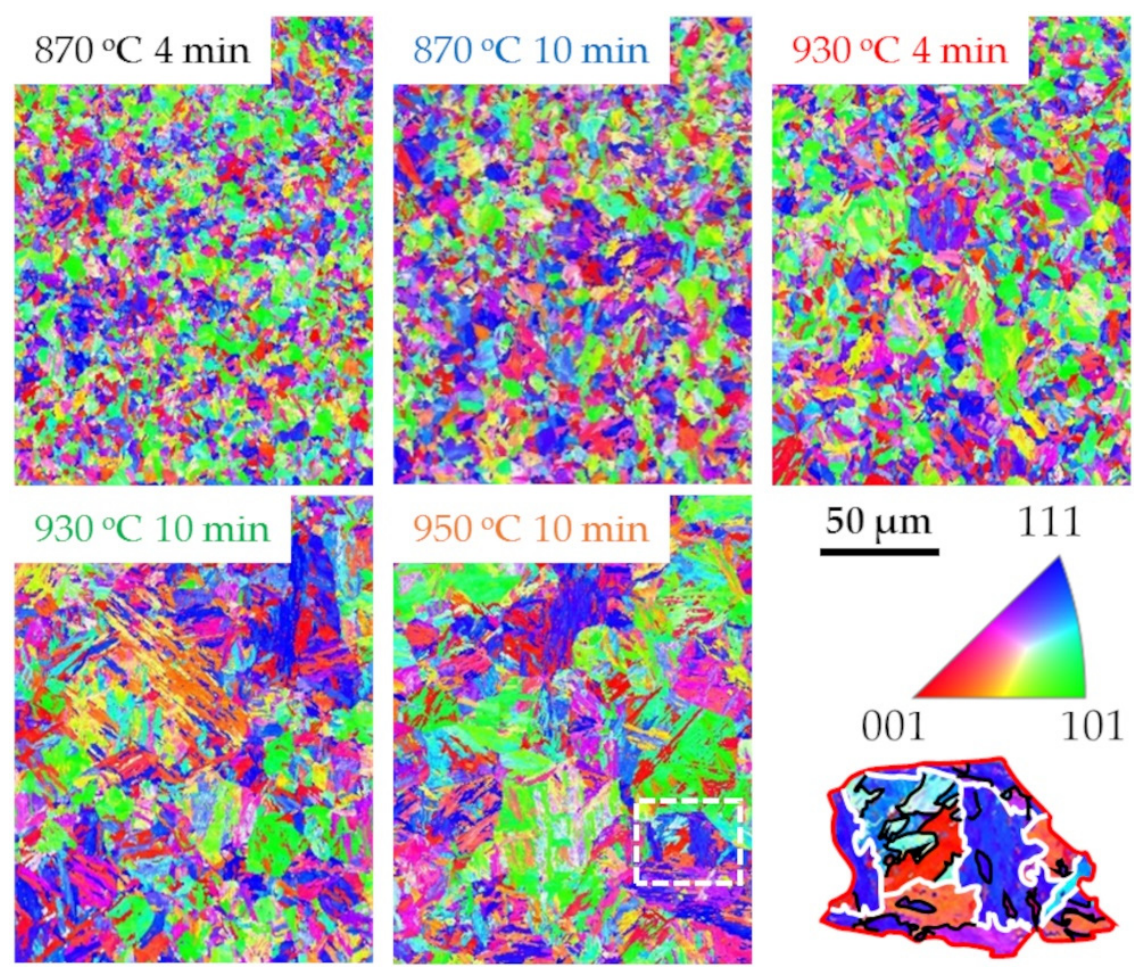

Figure 1. EBSD inverse pole figure maps of the low-carbon fully martensitic steel following five heat-treatments and the associated color-coded stereographic triangle (bottom right). Zoomed view of the region highlighted with a dashed box in the IPF map for $950{ }^{\circ} \mathrm{C} 10 \mathrm{~min}$ heat-treated material showing blocks (identified by solid black lines) and packets (identified by solid white lines) within a prior austenite grain (identified by solid red lines).

The IPF maps of the five heat-treated materials were used to reconstruct the PAGs. The PAG reconstruction was carried out using an open-source MATLAB-based software, MTEX [29-31] with an interface PAG_GUI [32]. This software utilizes the KurdjumovSachs orientation relationship to reconstruct PAGs from the IPF maps of the martensitic microstructure. The reconstructed IPF maps of the PAGs, using the IPF maps of the five heat-treated materials in Figure 1, are shown in Figure 2. A representative hierarchical microstructure consisting of blocks and packets within a PAG (highlighted in Figure 2) post-reconstruction is also shown in Figure 1. The orientation scatter of the PAGs in all five IPFs in Figure 2 shows that the heat-treated materials do not possess a pronounced texture. Also, in line with the block size, the PAG size in the microstructure (on average) increased significantly with the increasing heat-treatment temperature and time. The reconstructed PAG maps also show that in all of the five heat-treated steels, the PAG size is not homogeneous, i.e., they contain a distribution of small and large grains. 


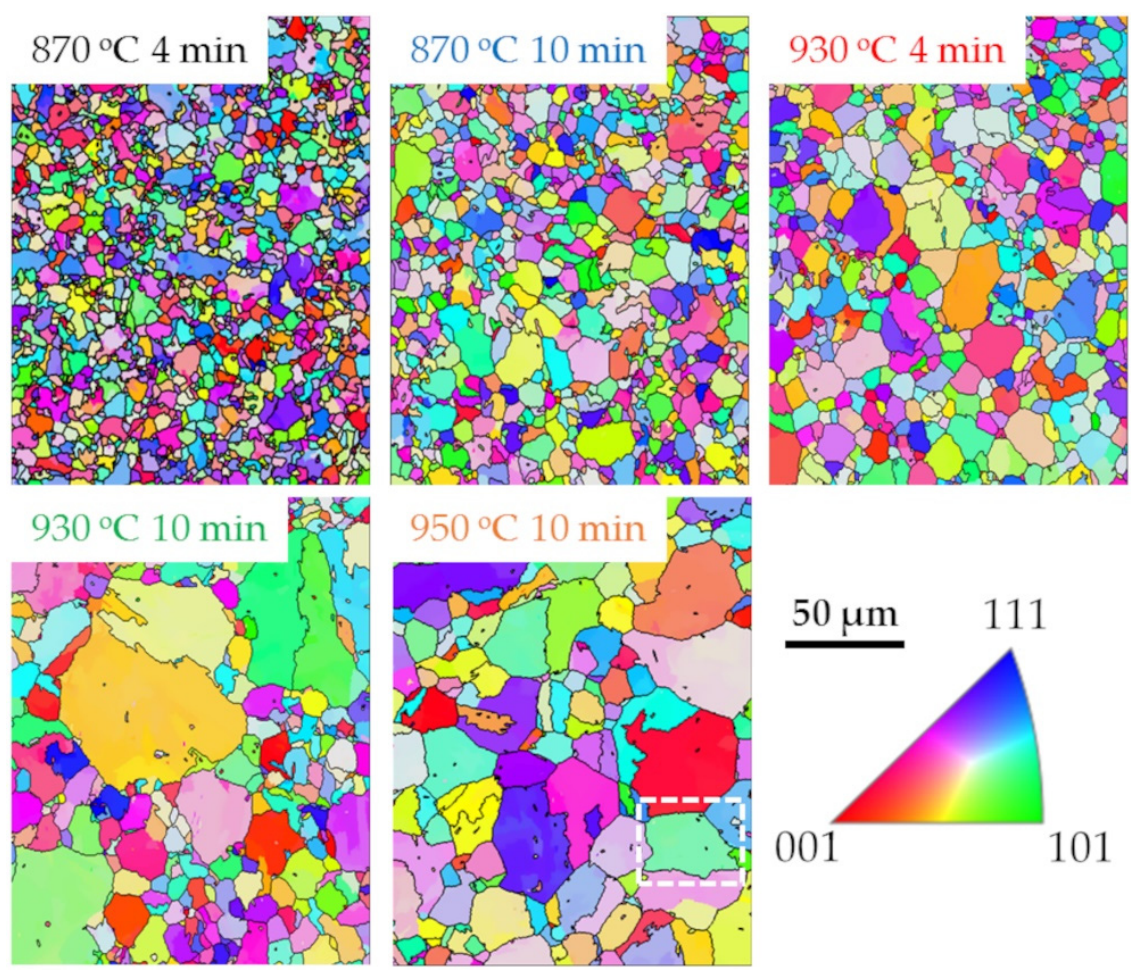

Figure 2. Reconstructed EBSD inverse pole figure maps of the prior austenite grains using the inverse pole figure maps of the five heat-treated martensitic steel (shown in Figure 1) and the associated color-coded stereographic triangle. The prior austenite grain identified in the bottom right of Figure 1 is highlighted with a dashed box in the IPF map for $950{ }^{\circ} \mathrm{C} 10$ min heat-treated material.

The PAG size in the five heat-treated materials was measured from multiple IPF maps of the reconstructed PAGs, as in Figure 2, following the Heyn linear intercept procedure [33]. The descending cumulative distribution function (CDF) of the PAG size in the five heattreated materials is shown in Figure 3a. The CDF curves represent the probability that the PAG size in a heat-treated material is greater than a given value on the $\mathrm{x}$-axis. As shown in Figure 3a, the probability of finding PAGs greater than a given value increases significantly with increasing the heat-treatment temperature and time. In other words, for a given probability, the PAG size increases significantly with the increasing heat-treatment temperature and time. The probability density plot of the PAG size in the five materials, shown in Figure 3b, does, however, show that the PAG size follows a bimodal distribution, especially in the $930{ }^{\circ} \mathrm{C} 10 \mathrm{~min}$ and $950{ }^{\circ} \mathrm{C} 10 \mathrm{~min}$ heat-treated materials. The bimodal distribution of the PAG size in the materials can be represented as a sum of two normal distributions, as follows:

$$
f_{\text {mix }}(x)=p \times \frac{1}{\sigma_{1} \sqrt{2 \pi}} e^{-\frac{1}{2}\left(\frac{x-\mu_{1}}{\sigma_{1}}\right)^{2}}+(1-p) \times \frac{1}{\sigma_{2} \sqrt{2 \pi}} e^{-\frac{1}{2}\left(\frac{x-\mu_{2}}{\sigma_{2}}\right)^{2}},
$$

where $p$ is the fraction, $\mu_{i}$ are the mean and $\sigma_{i}$ are the standard deviation of the two normal distributions. The parameters of the bimodal fit to the probability density plots of PAG size in the five materials are given in Table 1 . It can be noted from the data in Table 1 that not only both $\mu_{1}$ and $\mu_{2}$ increase, but their difference also increases with the increasing heat-treatment temperature and time, suggesting an increase in the bimodality of the PAG size consistent with the reconstructed PAG maps shown in Figure 2. 


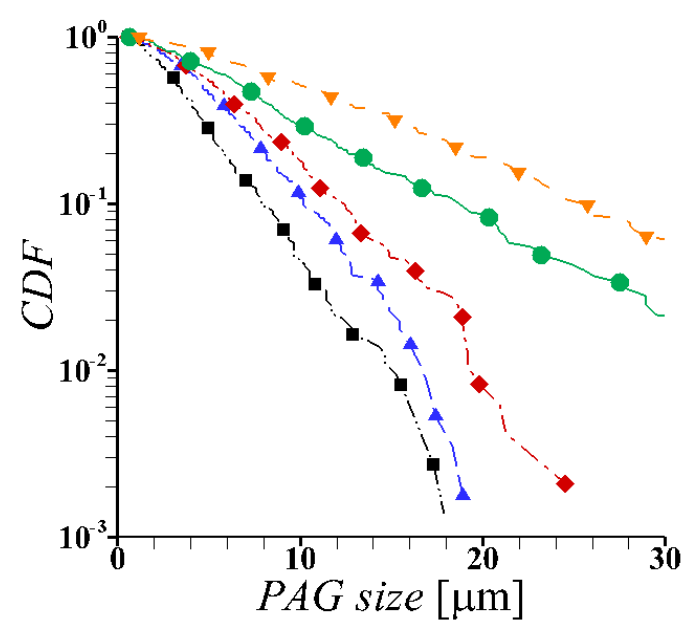

(a)

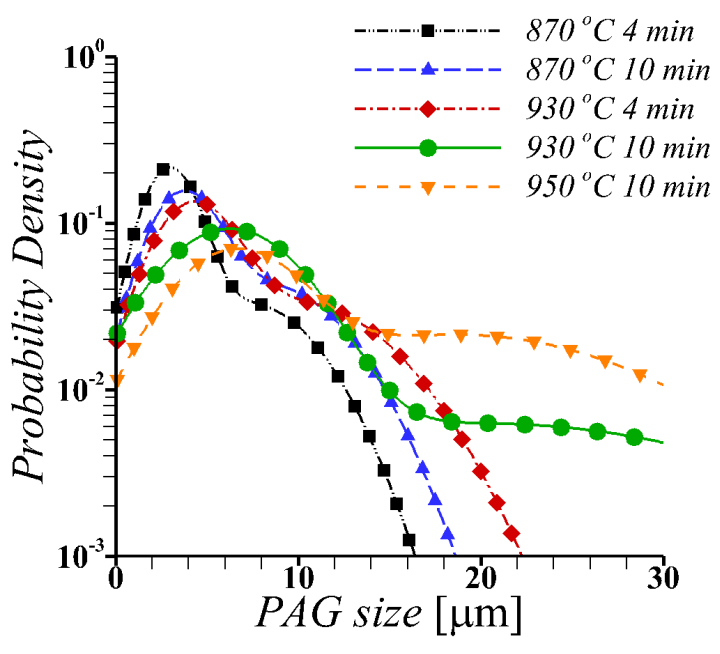

(b)

Figure 3. (a) The descending cumulative distribution function (CDF) and (b) the probability density function of the prior austenite grain (PAG) size in the low-carbon fully martensitic steel following five heat-treatments. The legend is the same for $(\mathbf{a}, \mathbf{b})$.

Table 1. Parameters of the bimodal fit (Equation (1)) to the probability density plots of the five heat-treated materials shown in Figure 3b.

\begin{tabular}{cccccc}
\hline Heat-Treatment Conditions & $\boldsymbol{p}$ & $\boldsymbol{\mu}_{1}$ & $\boldsymbol{\mu}_{2}$ & $\sigma_{1}$ & $\sigma_{2}$ \\
\hline $870^{\circ} \mathrm{C} 4 \mathrm{~min}$ & 0.7 & 2.9 & 7.3 & 1.4 & 3.4 \\
$870^{\circ} \mathrm{C} 10 \mathrm{~min}$ & 0.6 & 3.6 & 8.4 & 1.8 & 3.7 \\
$930^{\circ} \mathrm{C} 4 \mathrm{~min}$ & 0.6 & 4.2 & 10.0 & 2.1 & 4.6 \\
$930^{\circ} \mathrm{C} 10 \mathrm{~min}$ & 0.8 & 6.2 & 20.3 & 3.5 & 13.4 \\
$950^{\circ} \mathrm{C} 10 \mathrm{~min}$ & 0.5 & 6.5 & 18.8 & 3.2 & 9.5 \\
\hline
\end{tabular}

Although the PAG size in the five heat-treated materials follows a bimodal distribution, for the purpose of the comparison, we define a weighted average PAG size, $d_{G}$, which is approximately $4 \mu \mathrm{m}, 5.5 \mu \mathrm{m}, 6.5 \mu \mathrm{m}, 9 \mu \mathrm{m}$ and $13 \mu \mathrm{m}$ in the five heat-treated materials, $870{ }^{\circ} \mathrm{C}$ for $4 \mathrm{~min}, 870{ }^{\circ} \mathrm{C}$ for $10 \mathrm{~min}, 930{ }^{\circ} \mathrm{C}$ for $4 \mathrm{~min}, 930{ }^{\circ} \mathrm{C}$ for $10 \mathrm{~min}$ and $950{ }^{\circ} \mathrm{C}$ for $10 \mathrm{~min}$, respectively. The PAG reconstruction from the IPF maps of the five heat-treated materials also allowed us to approximately quantify the variation in the block and packet sizes with PAG size. Our analysis show that both the block and packet sizes on average increase linearly with increasing $d_{G}$, as has been reported previously $[17,34]$. The slope of the linear dependence of the average block, $d_{\text {block}}$, and packet, $d_{\text {packet }}$, sizes on $d_{G}$, however, are found to be different, and are roughly 0.11 and 0.22 for the linear dependence of $d_{\text {block }}$ on $d_{G}$ and that of $d_{\text {packet }}$ on $d_{G}$, respectively.

\subsection{Mechanical Response}

A comparison of the engineering stress $\left(\sigma_{e n g}\right)$-strain $\left(\varepsilon_{e n g}\right)$ response, obtained from the tension tests of the dog-bone specimens of the five heat-treated materials, is shown in Figure $4 \mathrm{a}$; while Figure $4 \mathrm{~b}$ compares the evolution of the true stress $(\sigma)$ normalized strainhardening rate, $1 / \sigma\left(d \sigma / d \varepsilon_{p}\right)$, as a function of the true plastic strain $\left(\varepsilon_{p}\right)$. As can be seen from the figures, qualitatively the tensile flow response of all five heat-treated materials is the same. The tensile flow response of all the materials exhibits an elastic response until the onset of yielding, which is followed by strain-hardening up until $\varepsilon_{\text {eng }} \approx 0.05$, at which point $1 / \sigma\left(d \sigma / d \varepsilon_{p}\right) \rightarrow 1$ and necking ensues. Post-necking, the load-bearing capacity of all five materials decreases gradually up until the final fracture. 


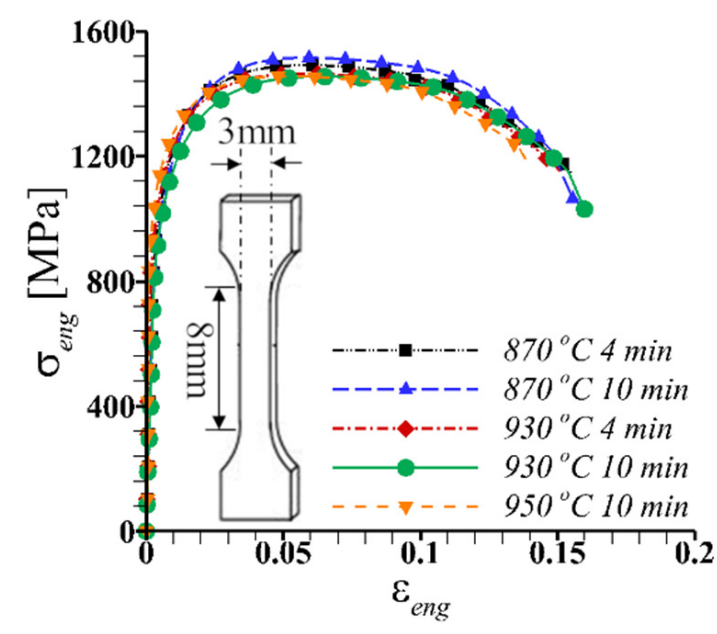

(a)

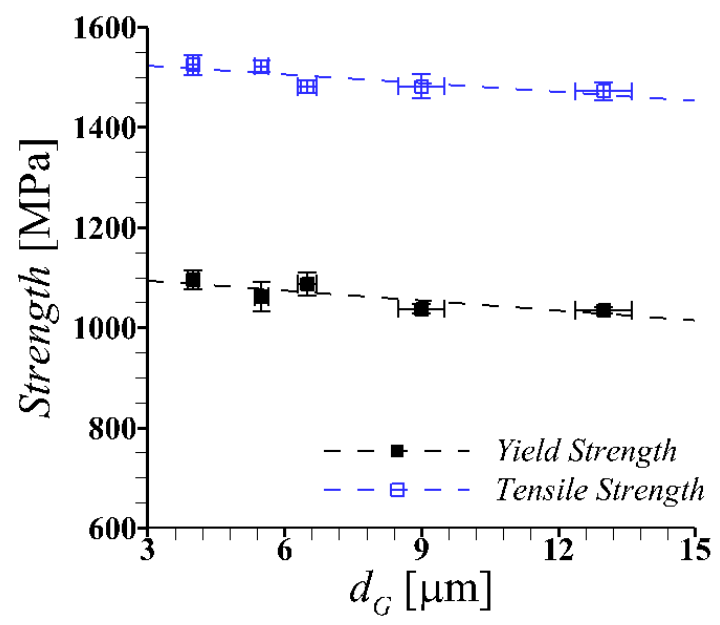

(c)

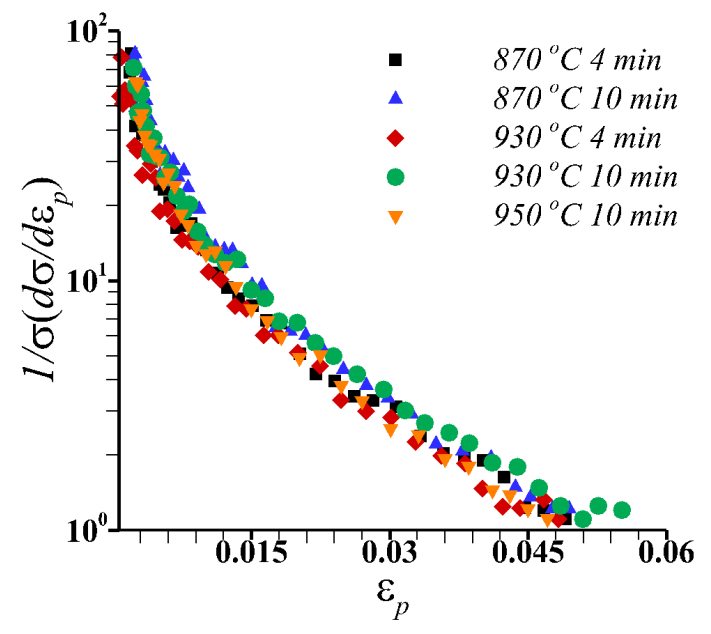

(b)

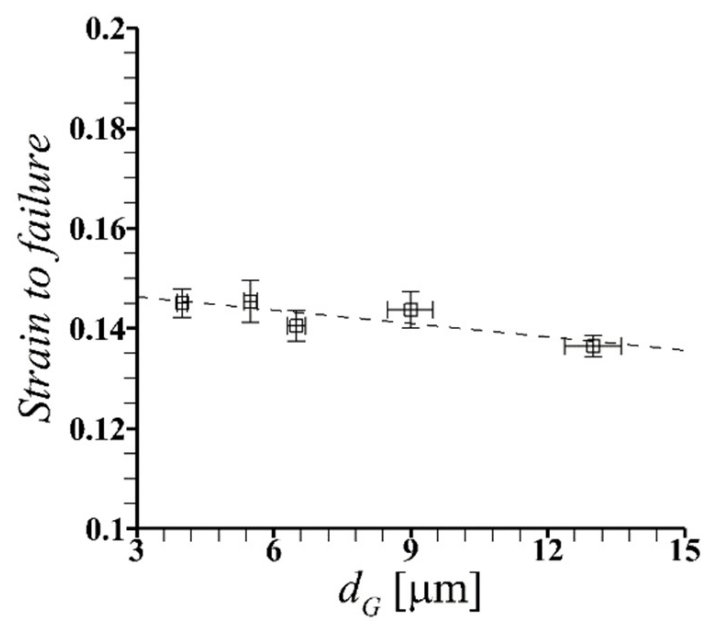

(d)

Figure 4. (a) Engineering stress-strain $\left(\sigma_{e n g}-\varepsilon_{\text {eng }}\right)$ response and (b) evolution of the true stress $(\sigma)$ normalized strainhardening rate, $1 / \sigma\left(d \sigma / d \varepsilon_{p}\right)$, with true plastic strain, $\varepsilon_{p}$, obtained from the dog-bone specimens of the five heat-treated martensitic steel. (c) Variation in the yield and tensile strengths and that of the (d) plastic strain to failure with average prior austenite grain size, $d_{G}$.

Next, the variation in the yield and tensile strengths and that of the plastic strain to failure with the average PAG size, $d_{G}$, are shown in Figure $4 \mathrm{c}, \mathrm{d}$. The error bars in Figure $4 \mathrm{c}$, d are plus/minus one standard error. As shown in the figures, the yield and tensile strengths, as well as the tensile ductility of the material, increase slightly with decreasing $d_{G}$. On average, a decrease in the value of $d_{G}$, from $13 \mu \mathrm{m}$ to $4 \mu \mathrm{m}$, results in approximately a $5 \%$ increase in yield strength, a $4 \%$ increase in tensile strength, and a $5 \%$ increase in tensile ductility.

The curves of the tensile force, $F$, normalized by the minimum cross-sectional area, $A_{0}^{\min }$, and the extension, $\delta$, normalized by the initial gauge length, $L_{0}$, of the single-edge notch specimens, as sown in Figure 5a, of the five heat-treated materials are compared in Figure 5b. As shown in Figure 5b, the linear portion of the normalized force-displacement curves of the single-edge notch specimens is independent of the heat-treatment condition, while the onset of the non-linearity and the maximum load-bearing capacity (maximum force) depend on the heat-treatment condition. The variation in the normalized maximum force, $F^{\max } / A_{0}^{\min }$, and that of the normalized maximum extension, $\delta^{\max } / L_{0}$, with $d_{G}$ are shown in Figure $5 c, d$. The error bars in the figures are plus/minus one standard 
error. As shown in the figures, the values of both $F^{\max } / A_{0}^{\min }$ and $\delta^{\max } / L_{0}$ increase with decreasing $d_{G}$. On average, a decrease in the value of $d_{G}$, from $13 \mu \mathrm{m}$ to $4 \mu \mathrm{m}$, results in an approximately $8 \%$ increase in the notch strength, i.e., $F^{\max } / A_{0}^{\min }$, and a $16 \%$ increase in the notch ductility, i.e., $\delta^{\max } / L_{0}$.

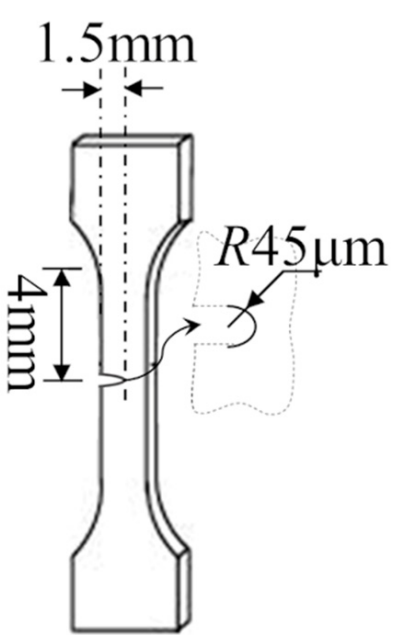

(a)

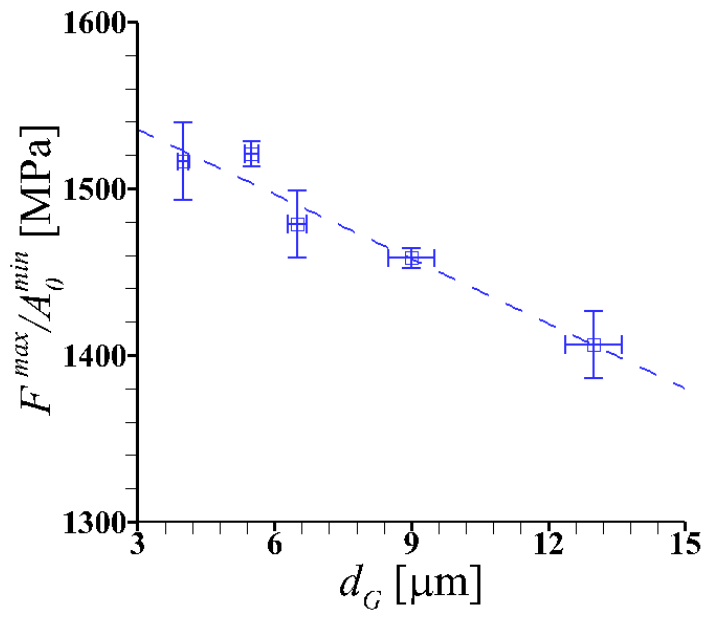

(c)

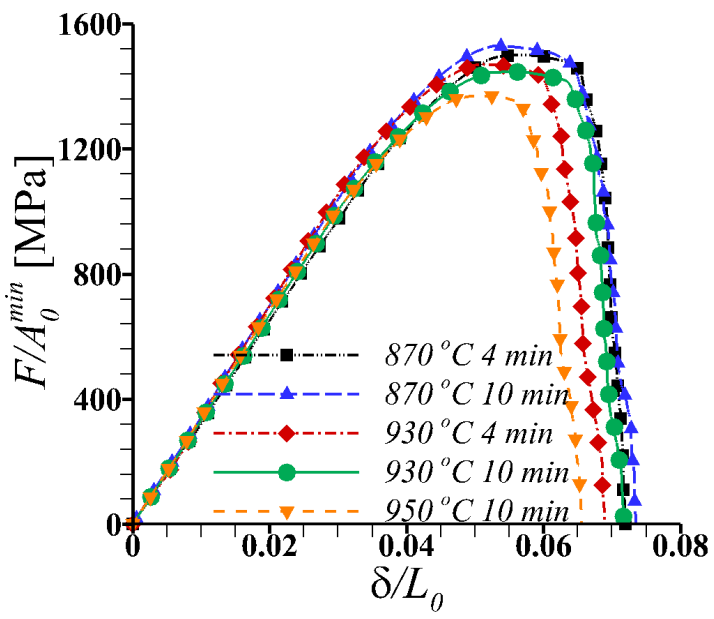

(b)

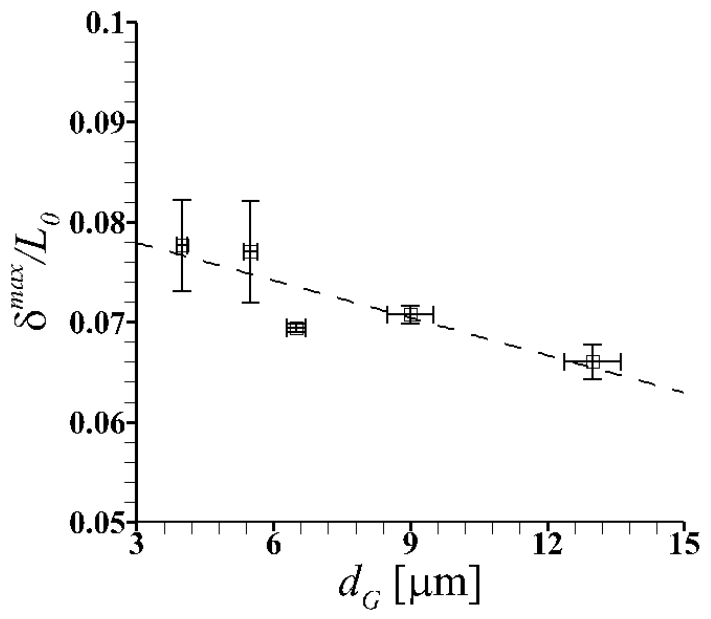

(d)

Figure 5. (a) Schematic of the single-edge notch specimen. (b) Normalized force-extension curves (force, $F$, is normalized by the minimum cross-sectional area, $A_{0}^{\min }$, and extension, $\delta$, is normalized by the initial gauge length, $L_{0}$ ) of the five heat-treated martensitic steel. (c) Variation in the normalized maximum force, $F^{\max } / A_{0}^{\min }$, and that of the (d) normalized maximum extension, $\delta^{\max } / L_{0}$, with average prior austenite grain size, $d_{G}$.

A series of optical images captured during the in situ tension tests of the single-edge notch specimens were directly used to extract crack-tip opening displacement, $\Delta$. The crack-tip opening displacement is an effective parameter to characterize the extent of local deformation at the notch root [35-37]. The value of $\Delta$ is defined as the distance between the intercepts of two orthogonal lines originating from the notch tip and the opposite sides of the notch, as shown schematically in Figure 6a. The critical value of $\Delta$ at the crack growth initiation, $\Delta_{c}$, was estimated as follows. First, the value of $\delta / L_{0}$, at which crack growth ensues, $\delta_{c} / L_{0}$, was identified from the force-displacement curve, as shown in Figure $5 b$, as the point at which the load bearing capacity of the specimen decreases rapidly. This was confirmed by visual inspection during the in situ tension tests. Second, the value of 
$\Delta_{c}$ was obtained from the $\Delta$ versus $\delta / L_{0}$ curve as the value of $\Delta$ at $\delta_{c} / L_{0}$ by exponential interpolation. The variation in the normalized critical crack-tip opening displacement, $\Delta_{c}^{n}=\left(\Delta_{c}-\Delta_{0}\right) / \Delta_{0}$, where $\Delta_{0}=91.6 \pm 1.7 \mu \mathrm{m}$ is the initial crack-tip opening, with $d_{G}$ is shown in Figure 6b. The error bars in the figure are plus/minus one standard error. As shown in Figure $6 \mathrm{~b}$, the value of $\Delta_{c}^{n}$ increases significantly with decreasing $d_{G}$. On average, a decrease in the value of $d_{G}$, from $13 \mu \mathrm{m}$ to $4 \mu \mathrm{m}$, results in an approximately $36 \%$ increase in the value of $\Delta_{c}^{n}$.

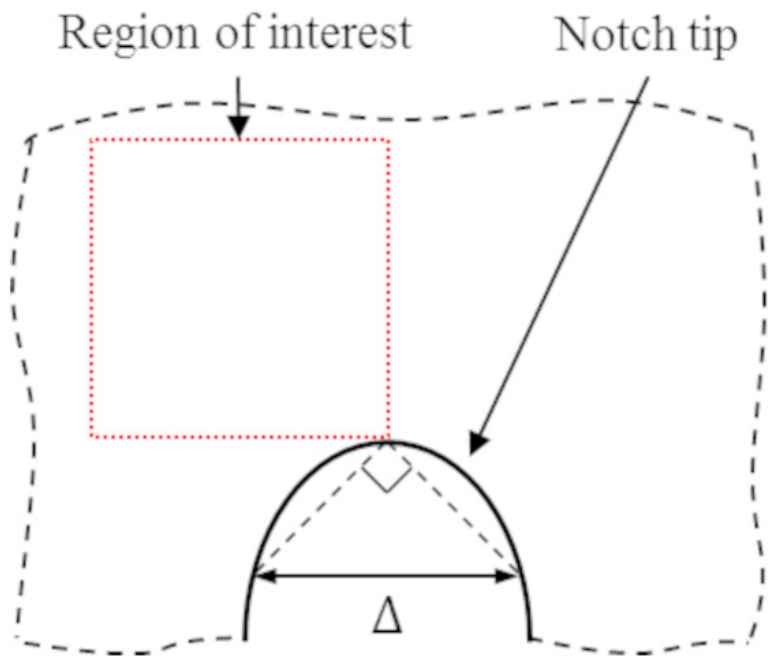

(a)

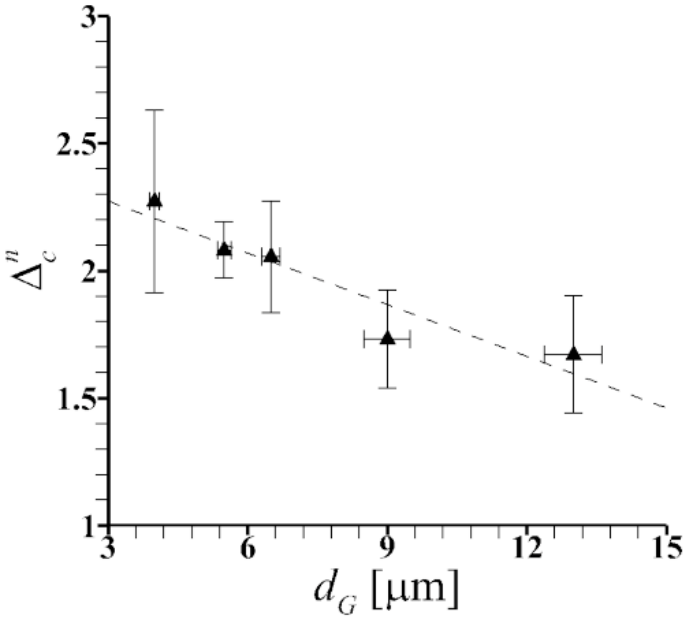

(b)

Figure 6. (a) Schematic showing a magnified view of the notch in a single-edge notch specimen and the definition of the crack-tip opening displacement, $\Delta$. (b) Variation in the normalized critical crack-tip opening displacement, $\Delta_{c}^{n}$, with average prior austenite grain size, $d_{G}$.

\subsection{Microscale Deformation Characteristics}

The series of high-resolution optical images of the polished surface (decorated with a fine dispersion of $1 \mu \mathrm{m}$ polycrystalline diamond particles) of all the specimens captured at regular intervals throughout the tensile deformation were also used to characterize the in-plane microscale strain fields via DIC. The distribution of the microscale strain along the tensile loading direction, $\varepsilon_{x x}$, in the reference configuration in a $270-$ by- $270 \mu \mathrm{m}^{2}$ region in the center of the gauge section of the dog-bone specimens of the five heattreated materials, deformed to a macroscopic tensile strain of $0.048 \pm 0.004$, is shown in Figure 7. As can be seen in Figure 4a, at this macroscopic tensile strain level, all the five materials are still undergoing uniform deformation, i.e., necking has not occurred yet. In Figure 7, the values of $\varepsilon_{x x}$ less than the average value of $\varepsilon_{x x}$ in the region of interest, $\varepsilon_{x x}^{b} \approx 0.05$, are whitewashed to highlight the regions of strain concentration or hot spots. As shown in the figure, the distribution of $\varepsilon_{x x}$ at the microscale is heterogeneous and the extent of this heterogeneity increases with the increasing heat-treatment temperature and time, even though all the specimens are undergoing homogeneous deformation at the macroscale. For instance, notice the increase in the size of the strain hot spots, i.e., regions with the values of $\varepsilon_{x x}>1.2 \varepsilon_{x x}^{b}$ with increasing heat-treatment parameters, especially for the materials heat-treated for $10 \mathrm{~min}$ at $930^{\circ} \mathrm{C}$ and $950{ }^{\circ} \mathrm{C}$. Quantitatively, the area fractions of $\varepsilon_{x x}>1.2 \varepsilon_{x x}^{b}$ are roughly $0.05,0.06$ and 0.07 in the materials heat-treated at $870{ }^{\circ} \mathrm{C}$ for $4 \mathrm{~min}, 870^{\circ} \mathrm{C}$ for $10 \mathrm{~min}$, and $930^{\circ} \mathrm{C}$ for $4 \mathrm{~min}$, respectively, while they are roughly 0.15 and 0.16 in the materials heat-treated at $930{ }^{\circ} \mathrm{C}$ for $10 \mathrm{~min}$ and $950{ }^{\circ} \mathrm{C}$ for $10 \mathrm{~min}$, respectively. 

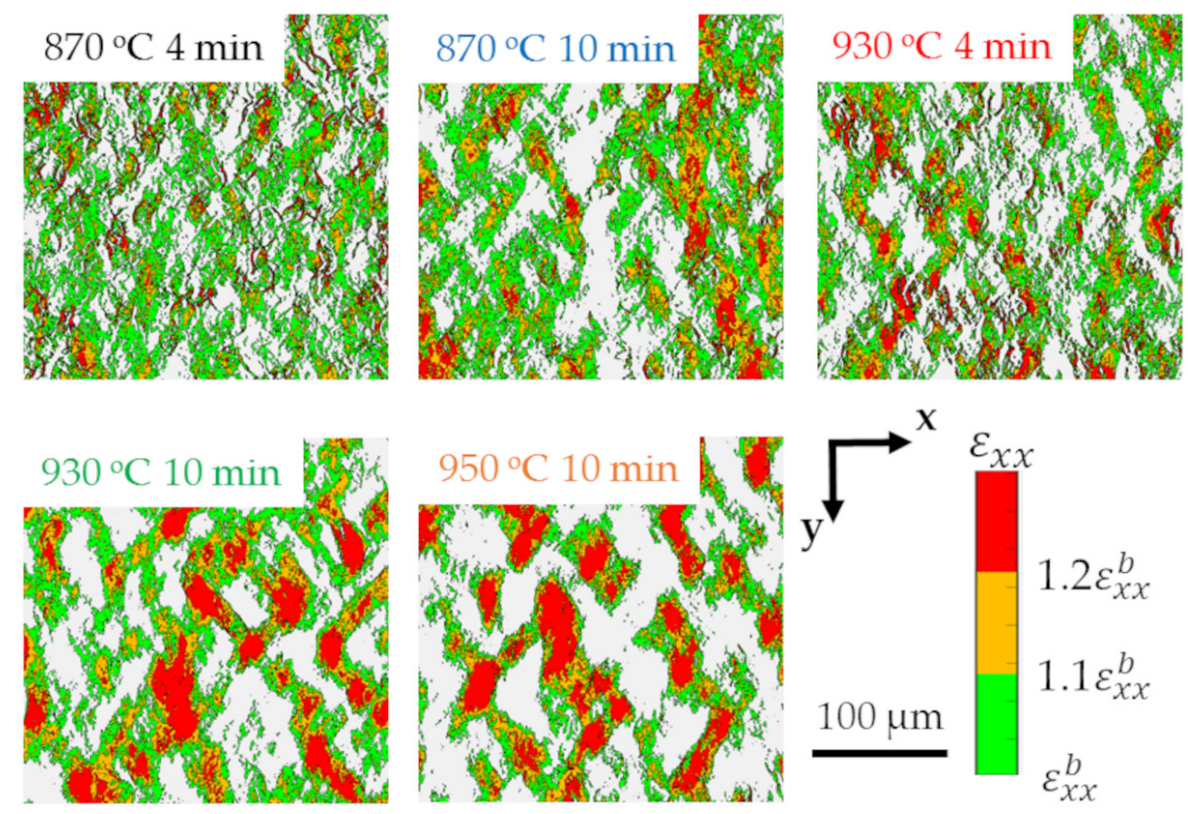

Figure 7. The distribution of axial strain, $\varepsilon_{x x}$, in a 270 -by- $270 \mu \mathrm{m}^{2}$ region in the center of the gauge section of the dog-bone specimens of the five heat-treated martensitic steel deformed to a macroscopic tensile strain of $0.048 \pm 0.004$. The loading direction is along the $x$-axis.

Similarly, the distribution of the $\varepsilon_{x x}$ in the reference configuration in a 135-by-135 $\mu \mathrm{m}^{2}$ region close to the notch (marked in Figure 6a as 'region of interest') in the single-edge notch specimens of the five heat-treated materials, deformed to a macroscopic normalized extension, $\delta / L_{0}$, of $0.05 \pm 0.003$, is shown in Figure 8 . As can be seen in Figure $5 b$, at this macroscopic deformation level none of the single-edge notch specimens have reached the maximum force, $F^{\text {max }}$. In Figure 8, the values of $\varepsilon_{x x}$ less than the average value of $\varepsilon_{x x}$ in the region of interest, $\varepsilon_{x x}^{b} \approx 0.09$, are whitewashed to highlight the regions of strain concentration or hot spots. As shown in the figure, in the single-edge notch specimens of all five materials, $\varepsilon_{x x}$ concentrates in wide bands that emanate from the corners of the deformed notch and are inclined at $\approx 45^{\circ}$ with respect to the loading axis. The distribution of $\varepsilon_{x x}$ within these bands is heterogeneous, but there is no obvious correlation between the heat-treatment parameters and the extent of heterogeneity. This is despite the observations made in Figures 5 and 6, which are that the macroscopic mechanical response and the value of the crack-tip opening displacement at the crack growth initiation of the single-edge notch specimens of the five materials significantly depend on the heat-treatment parameters (or simply $d_{G}$ ).

To further understand the effect of the heat-treatment parameters on the microscale deformation characteristics that in-turn affect the macroscopic mechanical response of the single-edge notch specimens of the five heat-treated materials, we now analyze the distribution of shear strain, $\varepsilon_{x y}$, close to the notch. The distribution of the $\varepsilon_{x y}$ in the reference configuration in a 135-by-135 $\mathrm{mm}^{2}$ region close to the notch (marked in Figure 6a as 'region of interest') in the single-edge notch specimens of the five materials, deformed to a macroscopic normalized extension, $\delta / L_{0}$, of $0.05 \pm 0.003$, is shown in Figure 9. As shown in the figure, in the single-edge notch specimens of all the five materials, the positive values of $\varepsilon_{x y}$ concentrate in triangular bands originating from the notch tip, while the values of $\varepsilon_{x y}$ are negative on the left side of these triangular bands. The distribution of $\varepsilon_{x y}$ within these triangular bands is heterogeneous, and the extent of heterogeneity or the size of the shear strain hot spots (regions with the values of $\varepsilon_{x y}>0.018$ ) increases with the increasing heat-treatment temperature and time. Also, unlike the distribution of $\varepsilon_{x x}$ shown in Figure 8, the overall area fraction of $\varepsilon_{x y}$ hot spots increases with the increasing heattreatment parameters, suggesting an increase in the propensity of shear deformation. 


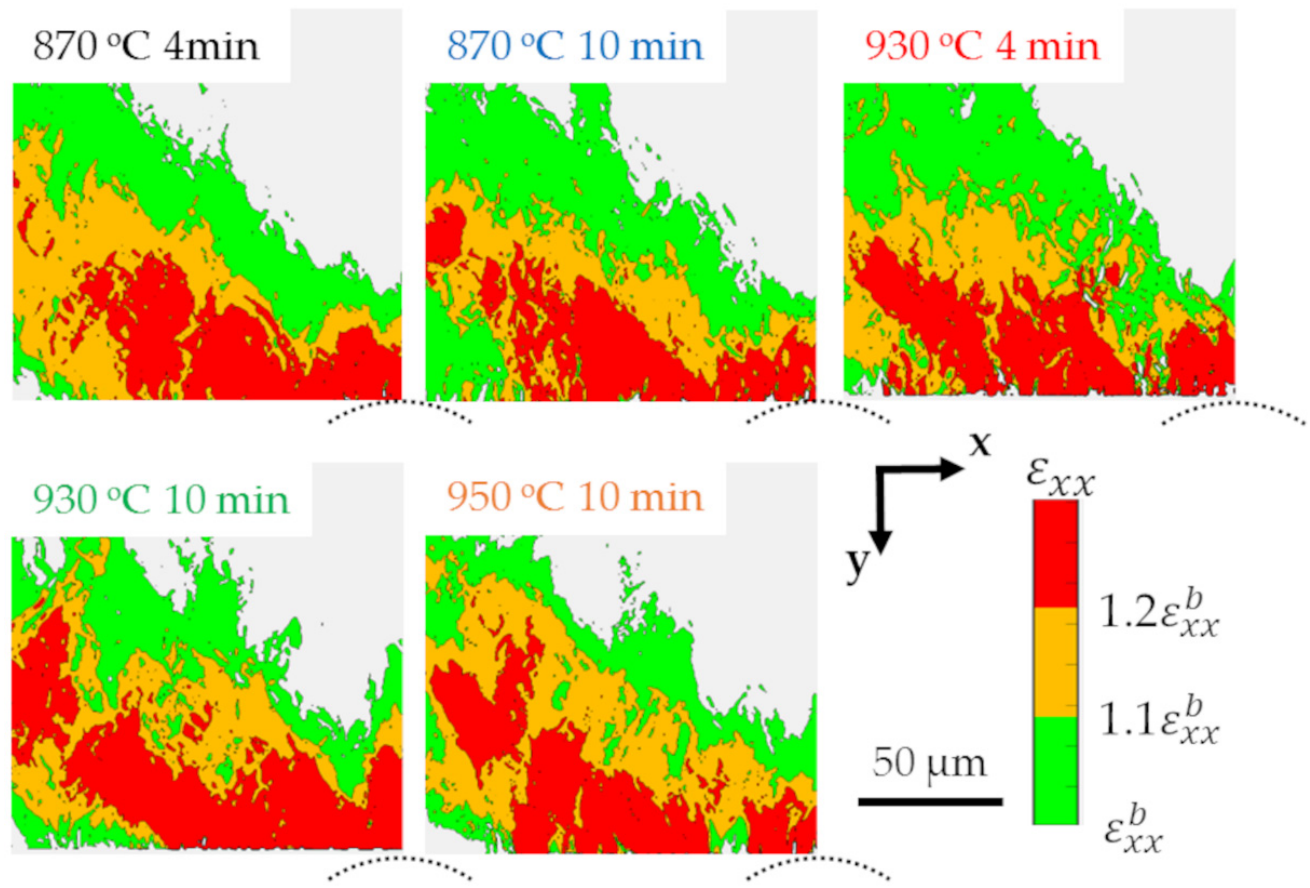

Figure 8. The distribution of axial strain, $\varepsilon_{x x}$, in a 135-by- $135 \mu \mathrm{m}^{2}$ region close to the notch (marked in Figure $6 \mathrm{a}$ as 'region of interest') in the single-edge notch specimens of the five heat-treated martensitic steel deformed to a macroscopic normalized extension, $\delta / L_{0}$, of $0.05 \pm 0.003$. The loading direction is along the $x$-axis and the dotted arcs mark the initial location of the notch tip.
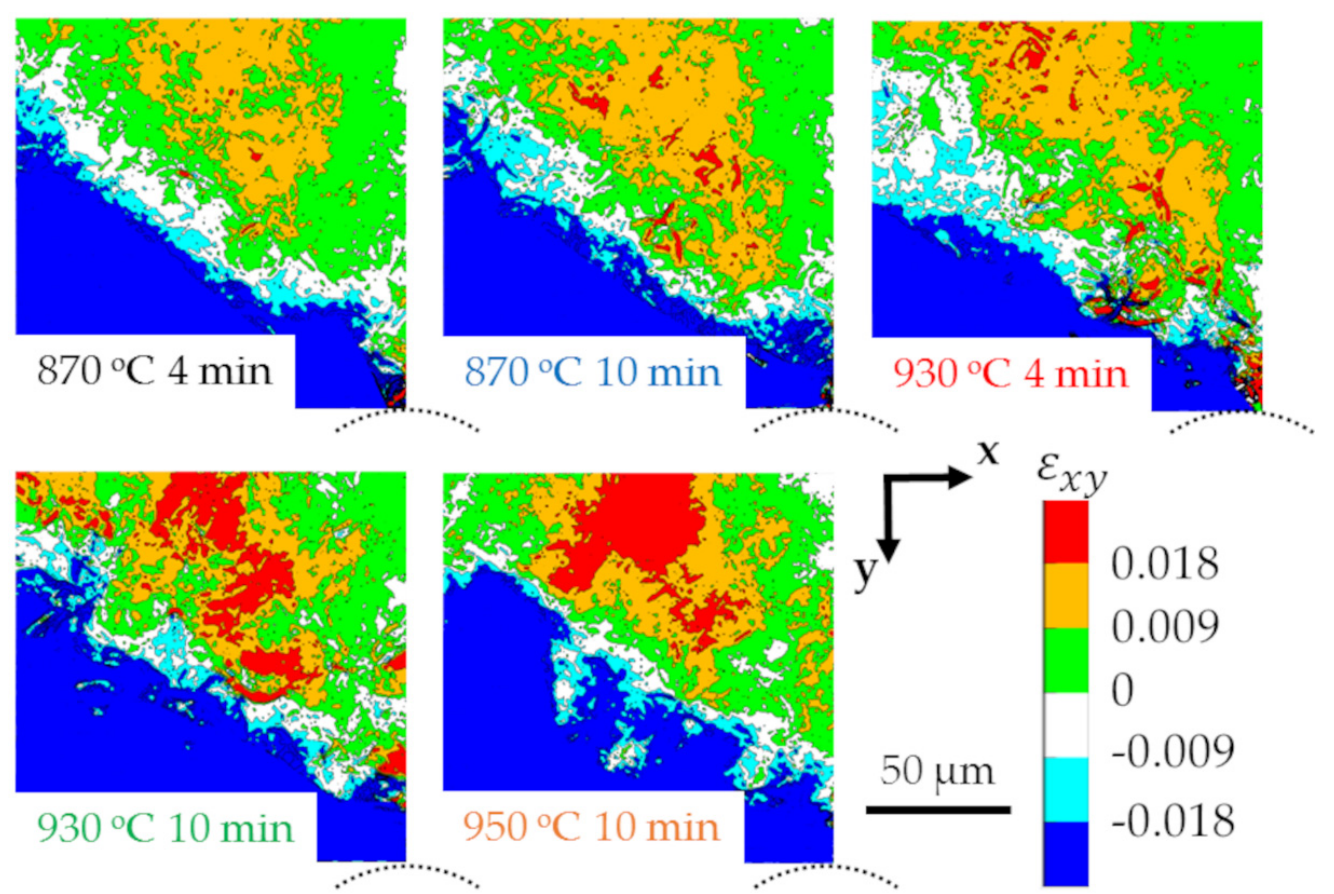

Figure 9. The distribution of shear strain, $\varepsilon_{x y}$, in a 135-by- $135 \mu \mathrm{m}^{2}$ region close to the notch (marked in Figure 6 a as 'region of interest') in the single-edge notch specimens of the five heat-treated martensitic steel deformed to a macroscopic normalized extension, $\delta / L_{0}$, of $0.05 \pm 0.003$. The loading direction is along the $\mathrm{x}$-axis and the dotted arcs mark the initial location of the notch tip. 


\subsection{Fracture Characteristics}

SE-SEM images showing the fracture surface morphology of the dog-bone specimens of the five heat-treated materials are shown in Figure 10. The images shown were taken from the center of the fracture surface of the specimens; however, we note that the fracture surface morphology throughout the fracture surface was roughly the same. Also, as shown in Figure 10, the fracture surface morphology of the dog-bone specimens of all five heattreated materials is qualitatively the same. The fracture surfaces of all the five materials exhibit a dimpled morphology, indicative of ductile fracture due to the nucleation, growth, and coalescence of microscale voids.

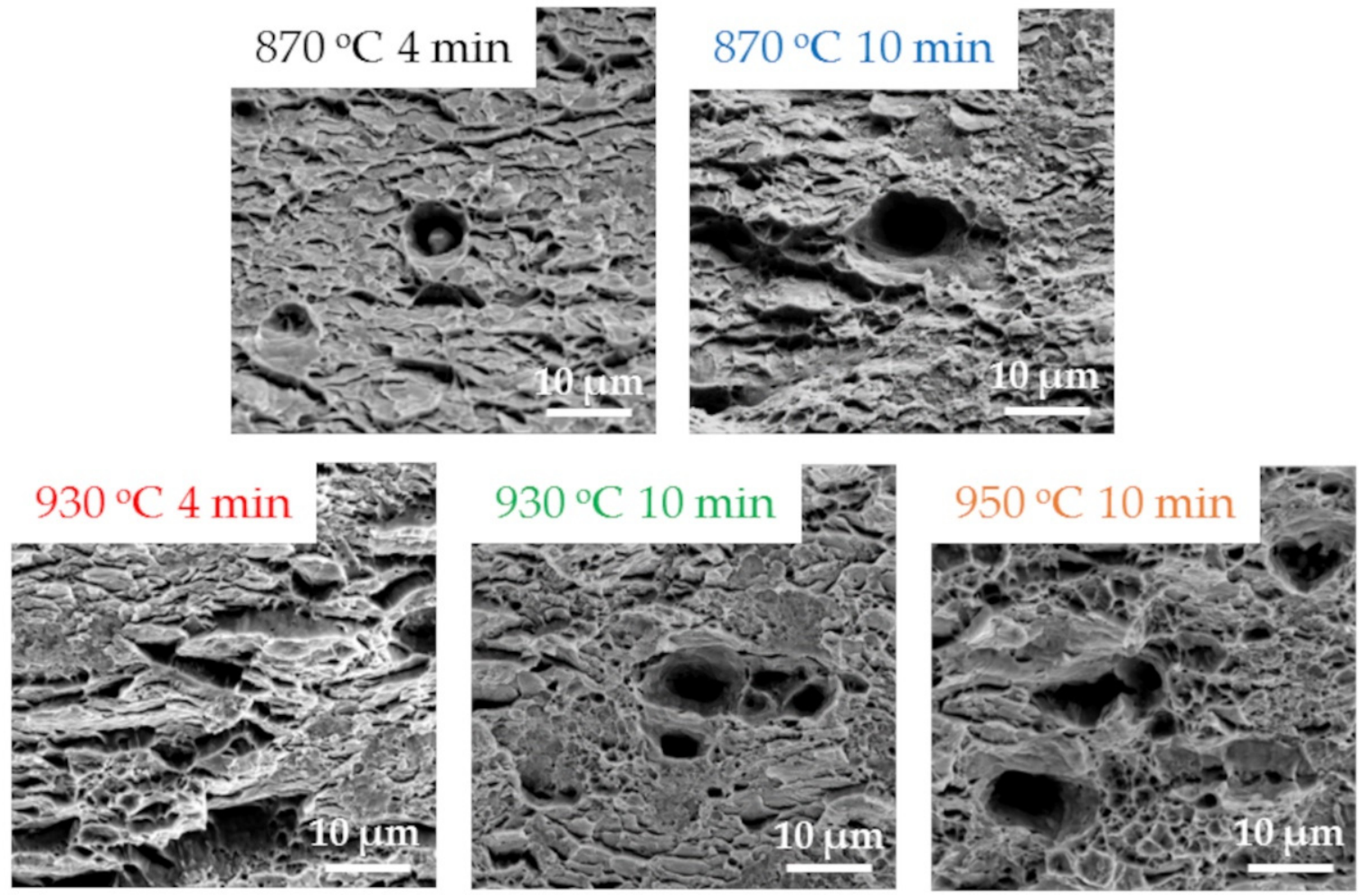

Figure 10. SE-SEM images taken from the center of the fracture surface of the dog-bone specimens of the five heat-treated martensitic steel. The loading direction is into the viewed plane.

The fracture surface morphology of the single-edge notch specimens of all five heattreated materials is also qualitatively the same. The fracture surfaces of the single-edge notch specimens of all five materials exhibit thumbnail-shaped regions close to the root of the initial notch. Also, for all five materials, the fracture surface morphology inside this thumbnail-shaped region is slightly different compared to the morphology outside of this region. SE-SEM images of the fracture surface of the single-edge notch specimens of the five materials inside the thumbnail-shaped region close to the initial notch tip (i.e., roughly $180 \mu \mathrm{m}$ away from the initial notch tip) and outside this region (i.e., roughly $880 \mu \mathrm{m}$ away from the initial notch tip) are shown in Figures 11 and 12, respectively. As shown in Figure 11, the fracture surface of all the five materials inside the thumbnail-shaped region exhibits a dimpled morphology, which is indicative of ductile fracture due to the nucleation, growth, and coalescence of microscale voids. While, as shown in Figure 12, the fracture surface of all the five materials outside the thumbnail-shaped region exhibits both dimples and quasi-cleavage-like features. 

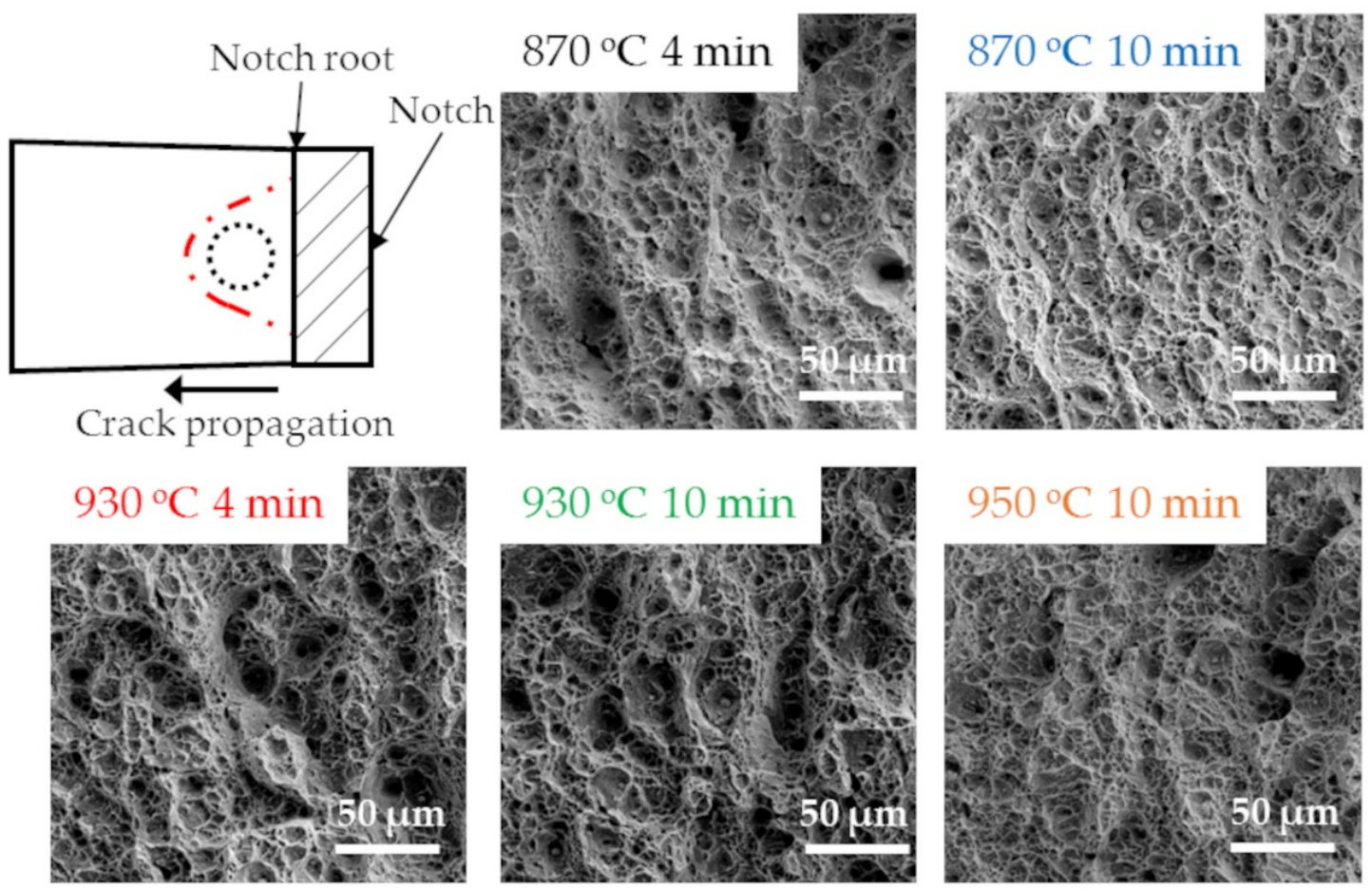

Figure 11. SE-SEM images taken from a location that lies within the thumbnail-shaped region on the fracture surface near the initial notch root of the single-edge notch specimens (as shown in the schematic) of the five heat-treated martensitic steel. The loading direction is into the viewed plane.
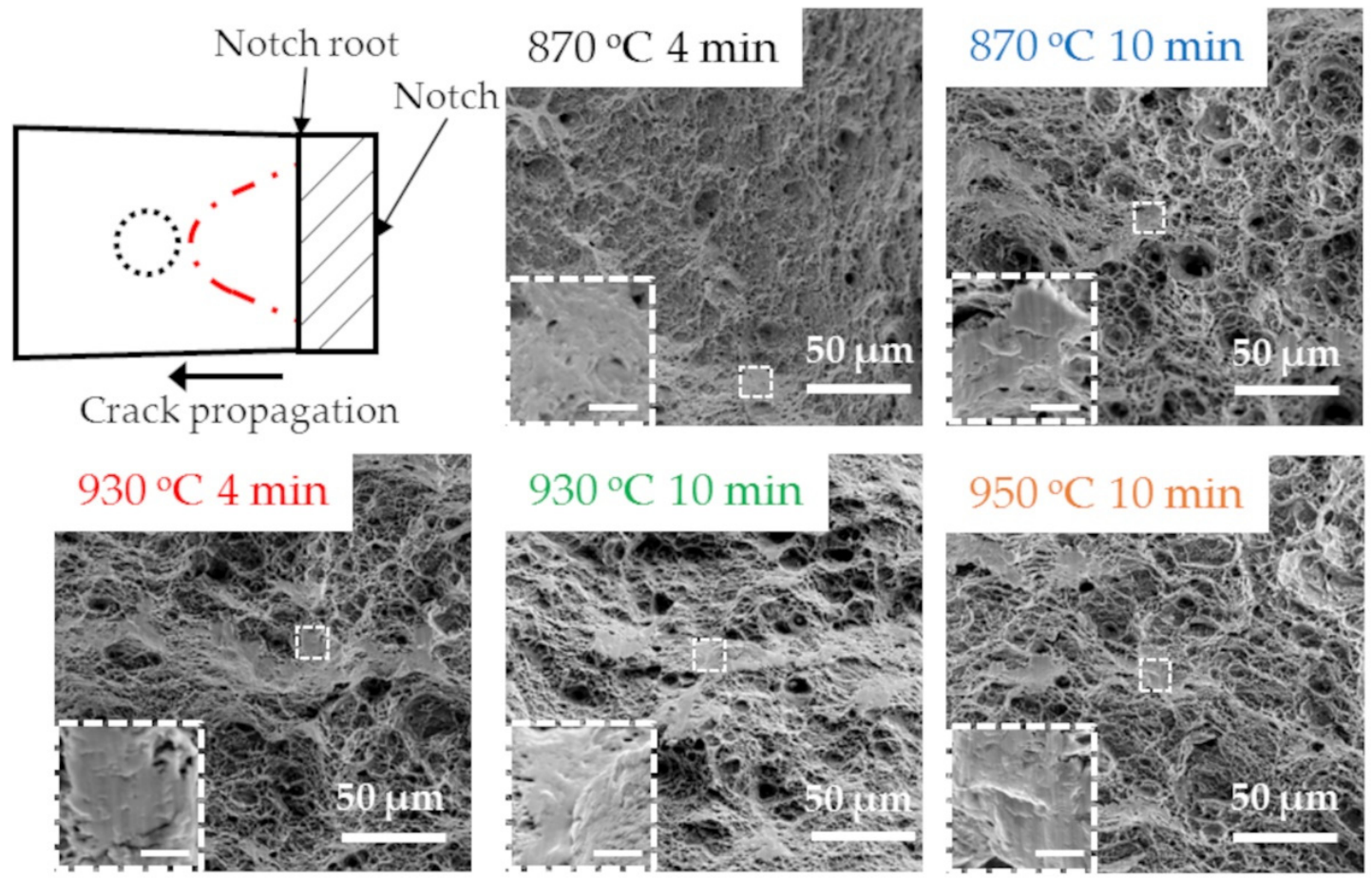

Figure 12. SE-SEM images taken from a location that lies outside the thumbnail shaped region on the fracture surface near the initial notch root of the single-edge notch specimens (as shown in the schematic) of the five heat-treated martensitic steel. The inset in the SEM images show the zoomed view of a representative quasi-cleavage region marked with a dashed box in the respective images. The scale bar for all the insets is $5 \mu \mathrm{m}$. The loading direction is into the viewed plane. 


\section{Discussion}

Our results show that both the average size and bimodality (distribution of small and large grains) of the PAGs in the low-carbon martensitic steel increase significantly with increasing heat-treatment temperature and time, for the range of temperature and time considered in this work. Nevertheless, the yield and tensile strengths, and ductility of the heat-treated materials, as characterized by the tension test of the dog-bone specimens, only decrease slightly with increasing average PAG size, $d_{G}$. While, the notch strength and ductility, and the crack-tip opening displacement at crack growth initiation, as characterized by the tension test of the single-edge notch specimens, decrease significantly with increasing $d_{G}$. This contrasts with any analysis based on classical engineering fracture mechanics that will predict a very similar fracture response for materials that exhibit a very similar stress-strain response under uniaxial tension, as is the case for the heat-treated martensitic steels considered here.

The microscale strain measurements show that in the single-edge notch specimens of the heat-treated martensitic steels there is an increase in the propensity of shear deformation with increasing the heat-treatment temperature and time. A quantitative representation of the extent of shear deformation in the single-edge notch specimens of the five heat-treated materials is shown in Figure 13. In Figure 13, we plot the variation in the area fraction of various levels of $\varepsilon_{x y}$ in the regions shown in Figure 9. The plot in Figure 13 basically shows the fraction of the area in the $\varepsilon_{x y}$ contour plots in Figure 9, with the value of $\varepsilon_{x y}$ being greater than a given value of $\varepsilon_{x y}$ on the x-axis. As shown in the figure, the area fraction of $\varepsilon_{x y}$ greater than a given value decreases with the increasing value of $\varepsilon_{x y}$, irrespective of the heat-treatment condition. However, the rate of the decrease of the area fraction with the increasing value of $\varepsilon_{x y}$ decreases with the increasing heat-treatment temperature and time for $\varepsilon_{x y}>0.005$. This analysis quantitatively confirms the increase in the propensity of shear deformation with increasing heat-treatment temperature and time (or simply $d_{G}$ ) in the martensitic steel. The increase in the propensity of shear deformation with increasing heat-treatment temperature and time also qualitatively rationalizes the presence of both dimples and quasi-cleavage-like features on the fracture surfaces of single-edge notch specimens of the heat-treated materials.

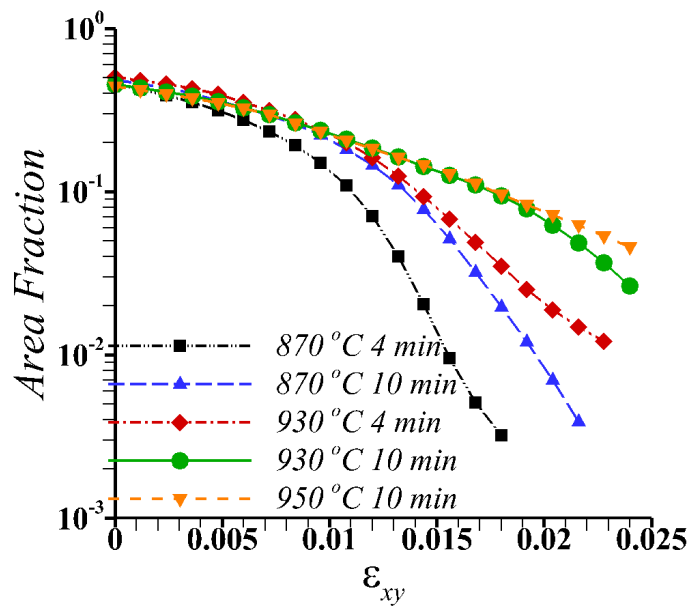

Figure 13. Variation in the area fraction of various levels of shear strain, $\varepsilon_{x y}$, in 135-by-135 $\mu \mathrm{m}^{2}$ region close to the notch in the single-edge notch specimens of the five heat-treated martensitic steel deformed to a macroscopic normalized extension, $\delta / L_{0}$, of $0.05 \pm 0.003$.

We hypothesize that the increase in the propensity of shear deformation in the singleedge notch specimens of the material is due to the increase in the bimodality of the PAGs in the material microstructure with increasing heat-treatment temperature and time. To prove this hypothesis, we also carried out a microstructure-based finite element analysis of singleedge notch specimens of materials with bimodal distributions of grain size. A schematic of 
the finite element model of one half of a two-dimensional plane strain single-edge notch specimen, with a zoomed view of a unimodal and bimodal microstructure close to the notch tip, is shown in Figure 14a. The specimen modeled has the same gauge length and notch dimensions as in the experiments and is subjected to x-axis symmetry boundary conditions along the plane of symmetry of the notch and $\mathrm{x}$-axis velocity on the free surface normal to the axis of the specimen. All the finite element analyses are carried out using a commercial finite element code, ABAQUS/Standard [38]. The finite element meshes use eight-node plane strain, CPE8R, elements of the ABAQUS/Standard element library. A 200-by-200 $\mu \mathrm{m}^{2}$ region close to the notch tip contains 400-by-400 elements, and a rather coarse mesh is used outside this region. Next, a bimodal distribution of grain microstructures, with grain sizes $2 \pm 0.2 \mu \mathrm{m}$ and $50 \pm 5 \mu \mathrm{m}$, is generated in the 200 -by-200 $\mu^{2}{ }^{2}$ fine mesh region close to the notch tip, using Voronoi tessellations. Specifically, five grain microstructures with a percentage of $2 \pm 0.2 \mu \mathrm{m}$ grain size as $100 \%, 80 \%, 70 \%, 60 \%$ and $50 \%$ are considered. These five microstructures are referred to as unimodal, 80-20 bimodal, 70-30 bimodal, 60-40 bimodal and 50-50 bimodal, respectively. In the calculations, all the grains in the material microstructure are modeled as rate-independent isotropic elastic-plastic materials within the finite strain $J_{2}$ flow theory. The Young's modulus and Poisson's ratio of the material is taken to be $210 \mathrm{GPa}$ and 0.3 , respectively. The plastic response of a grain of size $d_{G}$ is modeled using the following constitutive relation:

$$
\sigma=\sigma_{0}+A\left(d_{G}\right)^{-\frac{1}{2}}+B \varepsilon_{p l}^{n}
$$

where $\sigma_{0}=949 \mathrm{MPa}, A=296 \mathrm{MPa} \cdot \mu \mathrm{m}^{2}, B=1938 \mathrm{MPa}$ and $n=0.41$ are obtained from the experimentally measured dependence of yield strength on $d_{G}$, as shown in Figure $4 \mathrm{c}$, and average strain-hardenability of the material, as shown in Figure $4 \mathrm{a}$. Note that inside the 200 -by-200 $\mu \mathrm{m}^{2}$ fine mesh region area, where the grains are discretely modeled, $d_{G}$ is the size of the grain, while outside this region, $d_{G}$ is simply the average grain size.

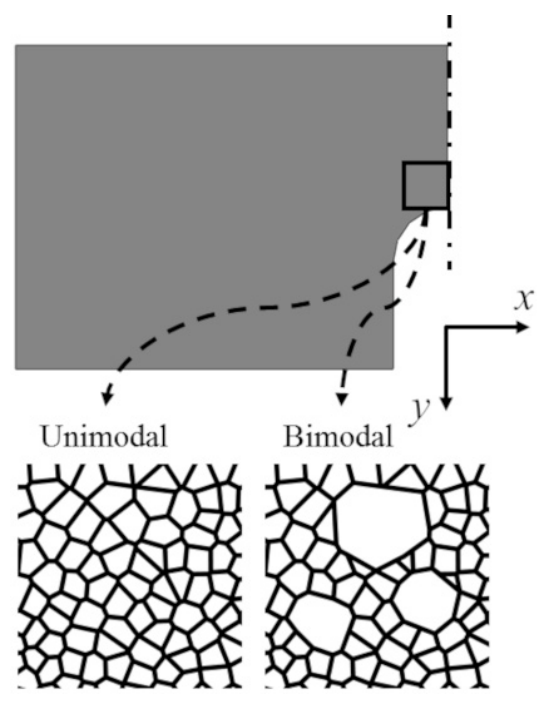

(a)

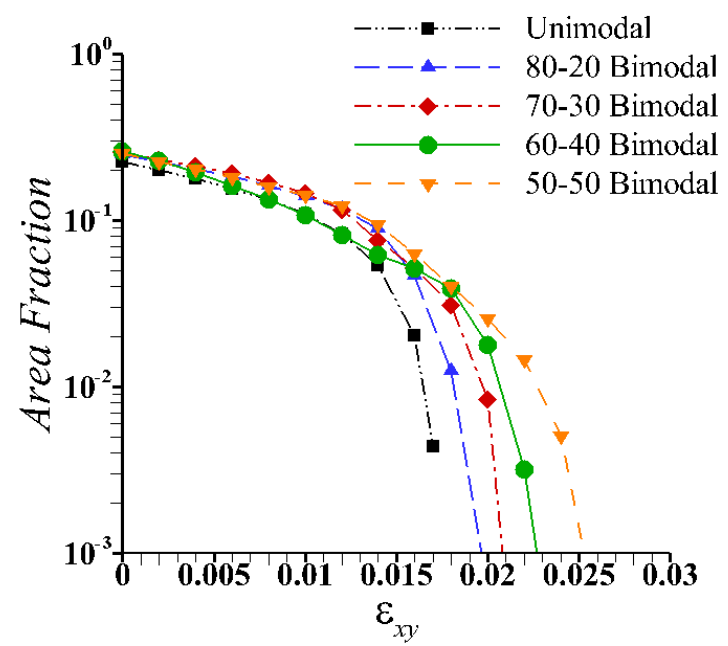

(b)

Figure 14. (a) Schematic showing the finite element model of one half of the single-edge specimen together with zoomed view of a unimodal and bimodal grain microstructure close to notch tip. (b) Variation in the area fraction of various levels of shear strain, $\varepsilon_{x y}$, in 200-by-200 $\mu \mathrm{m}^{2}$ region close to the notch in a unimodal and four bimodal microstructures deformed to a macroscopic normalized extension, $\delta / L_{0}$, of 0.015 .

A quantitative representation of the extent of shear deformation in the five finite element models is shown in Figure 14b. The figure shows the variation in the area fraction of various levels of $\varepsilon_{x y}$ in the 200-by-200 $\mu \mathrm{m}^{2}$ region close to the notch tip at the same 
macroscopic extension. As can be seen in the figure, the area fraction of $\varepsilon_{x y}$ greater than a given value decreases with the increasing value of $\varepsilon_{x y}$, irrespective of the extent of the bimodal grain distribution in the microstructure. However, the rate of the decrease in the area fraction with an increasing value of $\varepsilon_{x y}$ decreases with an increasing percentage of large grains for $\varepsilon_{x y}>0.015$. The results presented in Figure 14b prove our hypothesis that the propensity of shear deformation in the single-edge notch specimens increases with an increase in the bimodality of the PAGs in the material microstructure.

In summary, we have shown that even though the uniaxial stress-strain response of the low-carbon martensitic steel is not very sensitive to the variations in the heat-treatment parameters, their fracture response differs significantly. This is similar to dual-phase steels, for which it has been shown that the interaction of the heterogeneous deformation fields induced by the geometry of deformation, i.e., the presence of a notch in the single-edge notch specimens or three-point bending, and the material microstructure, i.e., distribution of a hard (martensite) and soft (ferrite) phases leads to an increase in the propensity of deformation localization, which significantly affects the fracture response of these materials [39-41]. The complex interactions of heterogeneous material microstructures and imposed loading conditions, and their effects on the observed mechanical response of materials, have also been observed under a host of other circumstances [42-44]. Although the low-carbon martensitic steel considered in this work is a single-phase material, their microstructure comprises a bimodal distribution of grains (i.e., PAG). Furthermore, the average size and the bimodality of the PAG distribution in the material increases with increasing heat-treatment temperature and time. The results of our in situ tests, together with microstructure-based finite element analysis, clearly elucidate that it is the interaction of the heterogeneous deformation fields induced by the notch and the bimodal PAG size distribution that leads to an increase in the propensity of shear deformation, and in turn degradation in the fracture response of the martensitic steel with increasing heat-treatment temperature and time.

\section{Conclusions}

In this work, we have quantified the effects of small variations in the heat-treatment parameters on the microstructure, and the deformation and fracture response of an ultra-high strength low-carbon martensitic steel. To this end, the material of interest was subjected to five heat-treatments and the prior austenite grain (PAG) microstructure in the resultant microstructures was characterized by reconstructing PAGs from the EBSD IPF maps of the martensitic microstructure. Next, the deformation and fracture response of all heattreated materials were characterized by in situ tension tests of dog-bone and single-edge notch specimens under a high-resolution optical microscope, allowing us to capture both the macroscopic mechanical response and the distribution of microscopic strains via microscale DIC. The in situ tension tests were also complemented with fractographic and microstructure-based finite element analyses. The key findings and conclusions of this work are as follows:

1. The average size and bimodality (distribution of small and large grains) of the PAG distribution in the low-carbon martensitic steel increase with increasing heat-treatment temperature and time;

2. The yield and tensile strengths, and ductility of the martensitic steel (as characterized by the tension tests of the dog-bone specimens) only decrease slightly with the increasing heat-treatment temperature and time (or average PAG size). However, due to the interaction of the heterogeneous deformation fields induced by the material microstructure (bimodal PAG size distribution) and the geometry of deformation (single-edge notch specimen), the fracture properties of the material (notch strength and ductility, and the crack-tip opening displacement at crack growth initiation) decrease significantly with increasing PAG heat-treatment temperature and time (or average PAG size); 
3. The interaction of the heterogeneous deformation fields induced by the bimodal material microstructure and the geometry of deformation (single-edge notch specimen) leads to an increase in the propensity of shear-induced deformation, which in turn gives rise to the strong dependence of the fracture properties of the martensitic steel on the average PAG size;

4. The final fracture of the dog-bone specimens of the heat-treated martensitic steel occurs by void nucleation, growth, and coalescence for the range of heat-treatment parameters considered. However, the fracture surfaces of the single-edge notch specimens of the material exhibit both dimples and quasi-cleavage-like features;

5. Achieving a uniform distribution of fine grains is an effective way to increase the strength levels and enhance the fracture properties of the low-carbon martensitic steels.

Author Contributions: Conceptualization, H.G.-A. and A.S.; methodology, X.Z., H.G.-A. and A.S.; validation, X.Z., H.G.-A., K.T.H. and A.S.; investigation, X.Z.; formal analysis, X.Z., H.G.-A., K.T.H. and A.S.; data curation, X.Z. and A.S.; writing-original draft preparation, X.Z.; writing-review and editing, X.Z., H.G.-A., K.T.H. and A.S.; supervision, A.S.; funding acquisition, K.T.H. and A.S. All authors have read and agreed to the published version of the manuscript.

Funding: This research was funded by the National Science Foundation, grant number DMR-1611380.

Institutional Review Board Statement: Not applicable.

Informed Consent Statement: Not applicable.

Data Availability Statement: Data are contained within the article.

Acknowledgments: The fully martensitic advanced high-strength steels were provided by the ArcelorMittal Global R\&D, East Chicago, IN, USA.

Conflicts of Interest: The authors declare no conflict of interest.

\section{References}

1. Kuziak, R.; Kawalla, R.; Waengler, S. Advanced high strength steels for automotive industry. Arch. Civ. Mech. Eng. 2008, 8, 103-117. [CrossRef]

2. Davies, G. Materials for Automobile Bodies; Butterworth-Heinemann; Butterworth-Heinemann: Waltham, MA, USA, 2012.

3. Joost, W.J. Reducing vehicle weight and improving US energy efficiency using integrated computational materials engineering. Jom 2012, 64, 1032-1038. [CrossRef]

4. Bouaziz, O.; Zurob, H.; Huang, M. Driving force and logic of development of advanced high strength steels for automotive applications. Steel Res. Int. 2013, 84, 937-947. [CrossRef]

5. Sato, M.; Utsumi, Y.; Watanabe, K. Ultra-High-Strength, Quench-type, Hot-Rolled Steel Sheets of 1620 MPa Grade for Automobile Door Impact Beams. Kobelco Technol. Rev. 2008, 28, 5.

6. Bok, H.-H.; Lee, M.-G.; Pavlina, E.J.; Barlat, F.; Kim, H.-D. Comparative study of the prediction of microstructure and mechanical properties for a hot-stamped B-pillar reinforcing part. Int. J. Mech. Sci. 2011, 53, 744-752. [CrossRef]

7. Altan, T.; Tekkaya, A.E. Sheet Metal Forming_Processes and Applications, 1st ed.; ASM International: Materials Park, OH, USA, 2012.

8. Morito, S.; Tanaka, H.; Konishi, R.; Furuhara, T.; Maki, T. The morphology and crystallography of lath martensite in Fe-C alloys. Acta Mater. 2003, 51, 1789-1799. [CrossRef]

9. Morito, S.; Huang, X.; Furuhara, T.; Maki, T.; Hansen, N. The morphology and crystallography of lath martensite in alloy steels. Acta Mater. 2006, 54, 5323-5331. [CrossRef]

10. Kitahara, H.; Ueji, R.; Tsuji, N.; Minamino, Y. Crystallographic features of lath martensite in low-carbon steel. Acta Mater. 2006, 54, 1279-1288. [CrossRef]

11. Ghassemi-Armaki, H.; Chen, P.; Bhat, S.; Sadagopan, S.; Kumar, S.; Bower, A. Microscale-calibrated modeling of the deformation response of low-carbon martensite. Acta Mater. 2013, 61, 3640-3652. [CrossRef]

12. Hata, K.; Fujiwara, K.; Wakita, M.; Kawano, K. Development of a Reconstruction Method of Prior Austenite Microstructure Using EBSD Data of Martensite; Nippon Steel \& Sumitomo Metal Corporation: Tokyo, Japan, 2017.

13. Krauss, G.; Matlock, D. Effects of strain hardening and fine structure on strength and toughness of tempered martensite in carbon steels. J. Phys. IV 1995, 5, C8-C51. [CrossRef]

14. Krauss, G. Martensite in steel: Strength and structure. Mater. Sci. Eng. A 1999, 273-275, 40-57. [CrossRef]

15. Krauss, G. Deformation and fracture in martensitic carbon steels tempered at low temperatures. Metall. Mater. Trans. A 2001, 32, 861-877. [CrossRef]

16. Tkalcec, I.; Mari, D.; Benoit, W. Correlation between internal friction background and the concentration of carbon in solid solution in a martensitic steel. Mater. Sci. Eng. A 2006, 442, 471-475. [CrossRef] 
17. Morito, S.; Yoshida, H.; Maki, T.; Huang, X. Effect of block size on the strength of lath martensite in low carbon steels. Mater. Sci. Eng. A 2006, 438-440, 237-240. [CrossRef]

18. Zhang, C.; Wang, Q.; Ren, J.; Li, R.; Wang, M.; Zhang, F.; Sun, K. Effect of martensitic morphology on mechanical properties of an as-quenched and tempered 25CrMo48V steel. Mater. Sci. Eng. A 2012, 534, 339-346. [CrossRef]

19. Prawoto, Y.; Jasmawati, N.; Sumeru, K. Effect of Prior Austenite Grain Size on the Morphology and Mechanical Properties of Martensite in Medium Carbon Steel. J. Mater. Sci. Technol. 2012, 28, 461-466. [CrossRef]

20. Hanamura, T.; Torizuka, S.; Tamura, S.; Enokida, S.; Takechi, H. Effect of Austenite Grain Size on Transformation Behavior, Microstructure and Mechanical Properties of 0.1C-5Mn Martensitic Steel. ISIJ Int. 2013, 53, 2218-2225. [CrossRef]

21. Kaijalainen, A.J.; Suikkanen, P.P.; Limnell, T.J.; Karjalainen, L.P.; Kömi, J.I.; Porter, D.A. Effect of austenite grain structure on the strength and toughness of direct-quenched martensite. J. Alloy. Compd. 2013, 577, S642-S648. [CrossRef]

22. Li, X.; Ma, X.; Subramanian, S.V.; Shang, C.; Misra, R.D.K. Influence of prior austenite grain size on martensite-austenite constituent and toughness in the heat affected zone of 700 MPa high strength linepipe steel. Mater. Sci. Eng. A 2014, 616, 141-147. [CrossRef]

23. Wang, J.; Singh, J.; Ramisetti, N. Process Influences on Press-Hardened Steel Microstructure and Impact Performance. Iron Steel Technol. 2016, 13, 124-132.

24. Białobrzeska, B.; Konat, Ł.; Jasiński, R. The influence of austenite grain size on the mechanical properties of low-alloy steel with boron. Metals 2017, 7, 26. [CrossRef]

25. Golem, L.; Cho, L.; Speer, J.G.; Findley, K.O. Influence of austenitizing parameters on microstructure and mechanical properties of Al-Si coated press hardened steel. Mater. Des. 2019, 172, 107707. [CrossRef]

26. ASTM E8/E8M Standard Test Methods for Tension Testing of Metallic Materials; ASTM International: West Conshohocken, PA, USA, 2021.

27. BS 8571 Method of Test for Determination of Fracture Toughness in Metallic Materials Using Single Edge Notched Tension (SENT) Specimens; British Standards Institution: London, UK, 2018.

28. Blaber, J.; Adair, B.; Antoniou, A. Ncorr: Open-source 2D digital image correlation matlab software. Exp. Mech. 2015, 55, 1105-1122. [CrossRef]

29. Bachmann, F.; Hielscher, R.; Schaeben, H. Grain detection from 2d and 3d EBSD data-Specification of the MTEX algorithm. Ultramicroscopy 2011, 111, 1720-1733. [CrossRef]

30. Hielscher, R.; Silbermann, C.B.; Schmidl, E.; Ihlemann, J. Denoising of crystal orientation maps. J. Appl. Crystallogr. 2019, 52, 984-996. [CrossRef]

31. Yardley, V.; Fahimi, S.; Payton, E. Classification of creep crack and cavitation sites in tempered martensite ferritic steel microstructures using MTEX toolbox for EBSD. Mater. Sci. Technol. 2015, 31, 547-553. [CrossRef]

32. Nyyssönen, T.; Isakov, M.; Peura, P.; Kuokkala, V.-T. Iterative determination of the orientation relationship between austenite and martensite from a large amount of grain pair misorientations. Metall. Mater. Trans. A 2016, 47, 2587-2590. [CrossRef]

33. ASTM E112-13 Standard Test Methods for Determining Average Grain Size; ASTM International: West Conshohocken, PA, USA, 2013.

34. Morito, S.; Saito, H.; Ogawa, T.; Furuhara, T.; Maki, T. Effect of austenite grain size on the morphology and crystallography of lath martensite in low carbon steels. ISIJ Int. 2005, 45, 91-94. [CrossRef]

35. Van Minnebruggen, K.; Verstraete, M.; Hertelé, S.; De Waele, W. Evaluation and Comparison of Double Clip Gauge Method and Delta 5 Method for CTOD Measurement in SE (T) Specimens. J. Test. Eval. 2015, 44, 2414-2423. [CrossRef]

36. Zhu, X.-K. Advances in Fracture Toughness Test Methods for Ductile Materials in Low-Constraint Conditions. Procedia Eng. 2015, 130, 784-802. [CrossRef]

37. Huang, Y.; Zhou, W. J-CTOD relationship for clamped SE(T) specimens based on three-dimensional finite element analyses. Eng. Fract. Mech. 2014, 131, 643-655. [CrossRef]

38. ABAQUS User's Mannual; Dassault Systèmes Simulia Corp.: Providence, RI, USA, 2018.

39. Zheng, X.; Ghassemi-Armaki, H.; Srivastava, A. Structural and microstructural influence on deformation and fracture of dual-phase steels. Mater. Sci. Eng. A 2020, 774, 138924. [CrossRef]

40. Liu, Y.; Fan, D.; Bhat, S.P.; Srivastava, A. Ductile fracture of dual-phase steel sheets under bending. Int. J. Plast. 2020, 125, 80-96. [CrossRef]

41. Liu, Y.; Fan, D.; Arróyave, R.; Srivastava, A. Microstructure-Based Modeling of the Effect of Inclusion on the Bendability of Advanced High Strength Dual-Phase Steels. Metals 2021, 11, 431. [CrossRef]

42. Chausov, M.; Maruschak, P.; Hutsaylyuk, V.; Śnieżek, L.; Pylypenko, A. Effect of complex combined loading mode on the fracture toughness of titanium alloys. Vacuum 2018, 147, 51-57. [CrossRef]

43. Yasniy, P.; Okipnyi, I.; Maruschak, P.; Panin, S.V.; Konovalenko, I. Crack tip strain localisation on mechanics of fracture of heat resistant steel after hydrogenation. Theor. Appl. Fract. Mech. 2013, 63, 63-68. [CrossRef]

44. Fang, Y.; Chen, X.; Madigan, B.; Cao, H.; Konovalov, S. Effects of strain rate on the hot deformation behavior and dynamic recrystallization in China low activation martensitic steel. Fusion Eng. Des. 2016, 103, 21-30. [CrossRef] 